\title{
COMPARISON OF THE EFFECT OF VIX FEAR INDEX ON STOCK EXCHANGE INDICES OF DEVELOPED AND DEVELOPING COUNTRIES: THE G20 CASE
}

Ömer İskenderoglu, Saffet Akdag

\section{Abstract}

This study aims to examine the potential causal relationship between the VIX and the indicator stock exchange index returns of G20 (9 developed and 10 developing) countries. Nineteen countries of the sample are G20 countries with available data. In this respect, the frequency domain Granger causality test of Breitung and Candelon (2006) is employed for the daily data between March 2011 and December 2017. The results obtained from the study indicate that there is no causal relationship between the VIX and the returns of the NASDAQ 100 index in developed countries. Similarly, no causal relationship is detected which runs from the VIX to the BIST100, BOVESPA, MERVAL, S\&P/BMVIPC and TADAWUL stock index returns in developing countries. As a result, the causal relationship is more tend to be found in developed countries in comparison to developing countries.

Keywords: Risk Appetite, Frequency Domain Causality, Stock Exchange Indexes

Jel Classification: $C 32, G 11, G 15$

\section{INTRODUCTION}

The risk word comes from the origins of "riscare" which means 'to dare' in Italian and expresses the likelihood of unwanted incidents. In a financial sense, risk presents the likelihood that a company would be exposed to a situation that may cause losses due to financial expectations or plans (Drake and Fabozzi, 2010). The risk is seen as one of the most complex and difficult-to-understand features of the investment process besides being one of the key elements of investment decisions. Because investors can have different attitudes and behaviors in the presence of risk. In this context, investors are distinguished into three groups regarding risk-taking behavior such as risk-seeking, risk-neutral and risk-averse (Başoğlu et al., 2001). Factors determining investment decisions of investors can be defined as the return and risk of the security to be invested in, the market risk and the attitudes of the investors towards the risk. Volatility, which constitutes a market risk, has an impact on financial markets. The increasing volatility of financial markets within the last two decades following the crisis in financial markets has attracted the attention of market regulators, investors, and academicians (Bildik and Elekdağ, 2004). Volatility, emerging in one of the integrated financial

Ömer İskenderoglu, Phd

Professor

Department of Business

Nigde Ömer Halisdemir University,

5100, Nigde, Turkey

E-mail: oiskenderoglu@ohu.edu.tr

Orcid: 0000-0002-3407-1259

Saffet Akdag, Phd (corresponding author)

Assistant Professor

Department of Banking and Finance

Tarsus University

E-mail: saffetakdag@tarsus.edu.tr

Address: Takbas Neighborhood, Kartaltepe Street, 33400, Mersin, Turkey

Orcid: 0000-0001-9576-6786 
markets along with the accelerated phase of globalization, also affects other financial markets due to the contagion brought about by financial globalization (Schmukler et al., 2003). For instance, the Wall Street Stock Market Crash of 1987 (the Black Monday) was one of the leading reasons for the volatility of the stock markets in developing countries at that time (Aggarwal et al., 1999). This process often referred to as the volatility spillover effect, is monitored by many investors and it steers their investment decisions. It has also been one of the major academic interests of finance science to design trade strategies, to identify and manage risks, and to clarify the dynamics and processes of market volatility due to the benefits of defining and predicting economic conditions (Han et al., 2015). In this context, the main volatility indices that are favored by the market and followed by investors are VIX (Volatility Index), GRAI (Global Risk Appetite Index), LCVI (Liquidity Credit and Volatility Index), ISI (Investor Sentiment Index), GFSI (Global Financial Stress Index), MOVE (Merrill Option Volatility Expectations Index) ve RAI (Risk Appetite Index). As a matter of fact, the VIX, which is expressed by many financial authorities as being determinative of the course of the stock market index and the currencies of developing countries, is being monitored by the central banks of many countries for policymaking. The VIX was first introduced by the Chicago Board Options Exchange in 1993. The VIX is an index that is calculated using the American type put and call option price volatility, including the S\&P 100 index with 30 days to maturity. Black and Scholes (1973) and Merton (1973) contributed to the development of the index. The VIX value of less than $20 \%$ indicates that the volatility has diminished, the investors' risk appetite has increased, and the investors are optimistic about the future. The VIX value in excess of $30 \%$ asserts that uncertainty and volatility have increased and that the market does not have suitable investment conditions. In this case, the investors are expected to exhibit a fear of investment attitude. It is also possible to claim that the increase in VIX deepens the information asymmetry and, under the existence of information asymmetry, investors exhibit a risk-averse attitude. Accordingly, the increases in VIX can also be accompanied by a rise in risk level. The increased market risk may cause investors to exhibit anxious and irrational attitudes.

To define the power of VIX on country indexes of developed and developing countries will be very useful to understand the potential effect differences among development. This revealing search of difference is selected as the aim of the study. Nevertheless, is a challenging process to determine the potential causal relationship between the VIX and stock market returns of both developed and developing countries. The generalization of the current literature in terms of the potential causality is not feasible due to the variety of results. This study aims to determine whether or not there is a causal relationship between the VIX and the indicator indexes of both developed and developing countries and, if there is a causal relationship, to examine it in the short-, medium- and long-run. Unlike other similar studies, this study examines the causal relationship in the short-, medium- and the long-run. Moreover, the study includes not only the results for a single country's stock exchange but also the developed and developing countries' stock exchanges for a possible similarity in the results.

This study consists of five parts. In the first part, basic concepts related to the subject are tried to be explained. In the second part, the previous studies which examined the relationship between the VIX and capital markets are mentioned. In the third part, the methods used in the study are explained, and the obtained findings by applying the methods are presented in the fourth part. The fifth part of the study contains a general evaluation.

\section{LITERATURE REVIEW}

During the literature review, a limited number of studies are found to investigate the relationship between the VIX and the stock market indexes of various countries. Also, there are studies that have been conducted to examine the relationship between the VIX and various financial indicators. The studies conducted on the VIX, stock market indexes and various financial indicators are summarized.

In their study conducted on the impact of the VIX on stock markets of 15 countries, Korkmaz and Çevik (2009) utilized the daily data of stock price and implied volatility indexes obtained from several countries such as Argentina, Brazil, Mexico, Peru, the Czech Republic, Hungary, Poland, Russia, Turkey, Indonesia, Korea, Malaysia, Taiwan, and Thailand over the period of 01.02.2004 - 03.17.2009 via the GJR-GARCH Model. Their findings asserted that VIX affects the stock exchange markets of 15 countries included in the analysis and obtained results are stated to be a proper guide for investors who would invest in stock markets of these countries. Sarwar (2012) conducted an analysis of the association of the daily data of the VIX and stock market returns obtained from BRIC countries with the VIX and stock market returns obtained from the USA over the period of 01.01.1993-12.31.2007 in order to determine whether or not the VIX serves as a proxy for investor fear in the stock markets of BRIC 
countries as well as the USA using Cross-correlation and Multiple regression methods. Obtained findings revealed the presence of a strong and adverse association between the VIX and the stock market indexes of the USA, India, China, and Brazil, whereas no similar association could not be detected for the stock market indexes of Russia. As a result, the VIX is determined as an investor fear indicator not only for the US stock markets, but also for the stock markets of China, Brazil and India. In another study, Heinonen (2013) examined the association between implied volatility and stock market returns using the daily data of the VIX and the S\&P 500 index over the period from 01.01. 2004 to 12.31. 2011 using the Regression Analysis and Granger Causality. The study concluded that no causal association is found between the VIX and the S\&P500 index returns. Nevertheless, according to the regression analysis results, investors are expected to act more sensitively toward the increase in the VIX. On the contrary, Kaya et al., (2015) found the presence of a significant long-term relationship between the VIX and the stock markets of OECD countries in their study that tested the effect of the VIX on stock markets in OECD countries via the ARDL model using the monthly data obtained from 34 member countries between January 1995- December 2013. Furthermore, the VIX turned out to be co-integrated with the stock markets under examination. Likewise, another study conducted by Ozair (2014) which aimed at detecting whether or not any causal relationship existed between the S\&P500 and the VIX determined a bilateral causality between the S\&P500 index and the VIX. It was also stated that shocks in the S\&P500 index had a permanent effect on the VIX. In the study conducted by Kaya and Çoşkun (2015), the effect of the VIX Index on the BIST-100 Index is revealed with Granger Causality and regression analysis. In the study, in which daily data obtained over the period of 1995-2014 were used, a statistically significant causality running from the VIX to BIST-100 Index was detected. According to another finding obtained by the authors, the VIX negatively affects the BIST-100 Index. Moreover, the VIX index was announced as the main indicator for securities investors in Turkey. In their study, Nazlioğlu et al., (2015) aimed at examining whether or not a volatility/risk transmission existed between the Dow Jones Islamic stock (DJIM) index and three conventional stock markets for the United States (SPA500), Europe (SPEU) and Asia (SPAS50TR) using daily data obtained over the period of 01.04.1999-09.20.2013 via the Variance Causality Test. It is asserted that the Dow Jones Islamic Stock Index, the SPA500 index, the SPEU index, and the SPAS50TR index respond to the VIX. Upon considering other studies that included the VIX Index as a variable, it was observed that Erdoğdu and Baykut (2016) examined the relationship between the Borsa Istanbul Bank Index (XBANK) and the VIX and MOVE indexes using daily data over the period of 12.10 .1998 - 12.31.2015 via the ARDL Bound, Granger, and TodaYamamato Causality Tests. According to the findings of the authors, there was no long-term relationship of the XBANK Index with the VIX and MOVE indexes, whereas a unilateral causality running from the VIX to the XBANK Index was detected. These indexes are stated to offer valuable information to policy decisionmakers and investors, particularly in evaluating possible turning points in the financial markets. In a more recent study conducted by Chen et al.,(2017); who investigated the predictive ability of international volatility risk for the daily stock market returns in China using daily data from the US, UK, France, Germany, Eurozone, Japan, and Hong Kong stock markets via the Panel Regression Analysis over the period of 01.04.2003-12.30.2013; it is asserted that volatility in the UK, France, Germany, the Eurozone, Japan, and Hong Kong stock markets, including the VIX, had an important and adverse impact on the Chinese Shanghai index returns. It also indicates that the international volatility risk indicator can be one of the leading indicators in explaining the Chinese stock returns. Huang and Wang (2017) analyzed the impact of investors' fear on the investors' investment behavior in the Taiwan stock market using the daily data of CSSD and CSAD variables obtained over the period of 01.01.2007-12.31.2014 by courtesy of the regression analysis. Their study concluded that there was a relationship between the VIX and the Taiwan stock exchange, and as a result, the changes in the VIX affected the behavior of investors. They also stated that the increase in the investors' fear triggered herding behavior. Another study conducted in the same year by Kula and Baykut (2017), who attempted to determine intertemporal interactions between the VIX and the BIST Corporate Governance Index using the daily data obtained over the period of 08.31.2007 - 12.31.2015 via the ARDL Bound Test, found a long-term relationship between the BIST Corporate Index and the VIX. It is also stated that both institutional and individual investors who would invest in financial markets should realize their investments according to the VIX data. Similar results were revealed by Sarwar and Khan (2017) who examined the impacts of the VIX on emerging markets indexes for the five Latin American emerging markets using the daily data obtained over the period of 06.01.2003-09.30.2014 via the Multiple Regression Analysis, so that the VIX had a negative and significant impact on the stock returns of the Latin American countries in all periods. 
It also indicated that the increase in US stock market uncertainty decreased the emerging market returns by both reducing average returns and increasing the variance of returns. The consequent year, Öner et. al., (2018) aimed at determining the relationship between the VIX and the stock market indexes of developing countries such as BIST 100 Index (Turkey), IPSA Index (Chile), Jalsha Index (South Africa), KS11 Index (South Korea), MICEX Index (Russia), Merval Index (Argentina), MXS Index (Mexico), SETI Index (Thailand), and TWICE Index (Taiwan) using the daily data obtained over the period of 10.23. 2006 - 05.10. 2017 via the Engel Granger Cointegration and Granger Tests. The causal relationship between the VIX and stock market indexes is found for developing countries in the sample. The only exception was the Merval stock market indicating no significant causal relationship. This outcome is a natural consequence of increased financial integration in the globalizing world and it demonstrates the increasing importance of the VIX for investors and policy practitioners. The first of the three most recently conducted studies in the literature review, Akdağ et. al., (2019), aimed at figuring out whether or not the VIX influences the returns of the tourism sector firms operating in 11 countries (Spain, USA, China, Italy, Turkey, Britain, Sweden, Denmark, Finland, Sri Lanka, and Greece) using the daily data obtained over the period of 01.01. 2013 - 12.31. 2017 via the Granger (1969) and Frequency Domain Causality Analysis. The findings of the study indicated that there was a causal relationship running from the change in the VIX towards the change in the tourism indexes of the countries except for the USA and Sri Lanka. Furthermore, a long-term relationship between the variables is detected. Investors who would invest in tourism companies are also recommended to monitor the VIX. The second study, Cheuathonghua, et. al., (2019), was conducted to analyze the effect of the VIX spillovers on 42 international equity markets in 25 developed and 17 developing countries using the daily data obtained over the period of 01.01. 1998 - 12.31. 2014 via the VAR and the multivariate multi-quantile model. The findings of the study revealed that the higher the US fear index (VIX), the lower the global stock returns and the larger the instability in international stock markets. In terms of geographical location, the VIX spillover effect is stated to be more pronounced on returns of the European stock markets and fluctuations of stock markets of Latin American countries. The third study, Qadan et. al., (2019), claimed that an increase in the VIX had a negative impact on future stock returns, whereas during the periods associated with a decrease in the VIX had a positive impact on future stock returns. It was stated that an increase in the VIX could have reflected an increase in investors' risk aversion and should have balanced their portfolios by increasing the diversity of their investments.

\section{DATA AND METHODOLOGY}

\subsection{Data}

In this study, the daily data of the VIX (also referred to as the "global risk appetite index") and the daily percentage returns of the leading stock indexes of 10 developed and ten developing countries are used. 19 of G20 countries have been able to be included in the analysis. Since one of the 20 countries is known as European Union Commission, it could have been only 19 countries in the G20 sample in this regard. As a result, the sample consists of nine developed and ten developing countries. The leading indexes of developed and developing countries included in this context are presented in Table 1.

The daily percentage returns of the stock indexes of developed and developing countries are

Table 1. Stock exchange indexes of developed and developing countries

\begin{tabular}{|c|c|c|c|c|c|}
\hline \multicolumn{3}{|c|}{ Developed Countries and Stock Exchange Indexes } & \multicolumn{3}{|c|}{ Developing Countries and Stock Exchange Indexes } \\
\hline Row & Country & Stock Exchange Index & Row & Country & Stock Exchange Index \\
\hline 1 & France & CAC40 & 1 & Turkey & BIST100 \\
\hline 2 & Germany & DAX & 2 & Brazil & BOVESPA \\
\hline 3 & G. Britain & FTSE100 & 3 & India & BSE 30 \\
\hline 4 & Italy & FTSEMIB & 4 & Indonesia & IDX \\
\hline 5 & South Korea & KOSPI & 5 & South Africa & JTOPI \\
\hline 6 & USA & NASDAQ100 & 6 & Argentina & MERVAL \\
\hline 7 & Japan & NIKKEI225 & 7 & Russia & MOEX \\
\hline 8 & Australia & S\&P ASX200 & 8 & China & SHANGHAI \\
\hline \multirow[t]{2}{*}{9} & Canada & S\&P TSX & 9 & Mexico & S\&P BMV IPC \\
\hline & & & 10 & Saudi Arabia & TADAWUL \\
\hline
\end{tabular}


utilized for the daily data spanning from March 2011 to December 2017. To obtain the highest amount of daily data paired with the selected sample countries, the analysis period needs to be limited. The index data of related countries are obtained from Bloomberg and CNBC internet sites, and the VIX data is collected from the Chicago Board Options Exchange website.

\subsection{Methodology}

In this study, the data are subjected to unit root tests with Extended Dickey-Fuller (ADF) and Philips-Perron tests to determine whether or not the data are stationary before conducting the causality analysis. After determining that the data are stationary, Breitung and Candelon (2006) frequency domain causality test is performed to determine whether or not there is causality between the variables by the Granger (1969) causality test and whether or not the causality between the variables is short-, medium- and long-term.

Yule (1926) pointed out that the time-series should be primarily stationary in analyses to be conducted with macroeconomic data. Similarly, Nelson and Plosser (1982) pointed out that the time-series must be stationary in order for them to be used in statistical analyses. Stationarity can be expressed as the fact that the mean of the time-series and its variance are independent of time. Commonly used stationarity testing includes Philips and Perron, Dickey-Fuller and Extended Dickey-Fuller tests (Saraç et al., 2016). Relevant unit root tests may differ regarding outcomes depending on assumptions, hypotheses, and sample sizes. For instance, the results of the ADF test are subjected to change according to the statistical confidence level, the lag length, and the sample size (Campbell and Perron 1991). In Balke and Fomby (1997) and Schwert (2002) studies, it was stated that the sample size of the Philips and Perron test provided more accurate results in a larger series.

The Granger Causality Test is based on testing whether or not there is a unilateral or bilateral causal relationship between two variables. In Granger (1969), causality is expressed as the measurement of the use of past values of $X$ for the prediction of $Y$ in comparison to not using the past values of $X$. According to Granger (1988), it can be concluded that X Grangercauses $Y$ if the use of its past values makes the prediction more successful. In the performed causality analyses, measurements are made with $\mathrm{F}$ and Wald tests. In this context, the Granger Causality Test can be used to find out whether $X$ is the Granger-cause of $Y$ or vice versa, or a bilateral Granger causality exists between $X$ and $Y$, or even no causality at all. However, although the Granger Causality Test indicates a causal relationship between the variables, the Wald and $F$ tests used in the method may reveal the long-run relationship by ignoring the short-run relationship (İskenderoğlu and Akdağ, 2017).

In order to solve this problem, Geweke (1982), Hosoya (1991) and Yao and Hosoya (2000) proposed the measurement of causality at frequencies based on the decomposition of spectral density functions. Frequency domain causality is preferred since it allows Granger causality to be evaluated at different frequencies and it is an easily applicable model being based on a set of linear limitations (Yanfeng, 2012: 58). The spectral density function, which is the basis of frequency domain causality, can be expressed by the following equation (Kratschell and Schmidt, 2012):

$$
f_{x}(\omega)=\frac{1}{2 \pi}\left\{\left|\Psi_{11}\left(e^{-i \omega}\right)\right|^{2}+\left|\Psi_{12}\left(e^{-i \omega}\right)\right|^{2}\right\}
$$

However, the problem of using the $\mathrm{F}$ test in the implementation of the relevant tests has been solved by applying the proposed linear limitations in Breitung and Candelon (2006). The Granger Causality Test examines a single test statistic for the variables involved in the analysis, whereas a nonlinear causality test is performed with the Frequency Domain Causality Test. Granger causality at different frequencies is expressed by Geweke (1982) and Hosoya (1991) via the equation below:

$$
\begin{aligned}
& M_{y \rightarrow x}(\omega)=\log \left[\frac{2 \pi f_{x}(\omega)}{\left|\Psi_{11}\left(e^{-i \omega}\right)\right|^{2}}\right]= \\
& =\log \left[1+\frac{\left|\Psi_{12}\left(e^{-i \omega}\right)\right|^{2}}{\left|\Psi_{11}\left(e^{-i \omega}\right)\right|^{2}}\right]
\end{aligned}
$$

If $\left|\Psi_{12}\left(e^{-i \omega}\right)\right|=0$ according to the equality, no causality from variable $y$ to variable $x$ would occur at any frequency $\omega$ (Ciner, 2011:500). Breitung and Candelon (2006) suggest a new method to test the null hypothesis offering that there is no causality in their study.

$$
\text { If } M_{y \rightarrow x}(\omega)=0,\left|\Psi_{12}\left(e^{-i \omega}\right)\right|=0 \text {, the following }
$$
equation is used:

$$
\Psi(L)=\Theta(L)^{-1} G^{-1} \text { ve } \Psi_{12}(L)=-\frac{g^{22} \Theta_{12}(L)}{|\Theta(L)|}
$$

$g^{22}$ expresses the low diagonal elements of the matrix $G^{-1}$, while $|\Theta(L)|$ denotes the determinant of $\Theta(L)$. 
In this case, the hypothesis claiming that " $y$ " does not cause " $x$ " at frequency " $\omega$ " can be tested by the following equation (Bodart and Candelon, 2009):

$$
\begin{aligned}
& \left|\Theta_{12}\left(e^{-i \omega}\right)\right|=\mid \sum_{k=1}^{p} \Theta_{12, k} \cos (k \omega)- \\
& -\sum_{k=1}^{p} \Theta_{12, k} \sin (k \omega) i \mid=0
\end{aligned}
$$

Since $\Theta_{12, k}$ denotes $(1,2)$ element of $\Theta_{k},\left|\Theta_{12}\left(e^{-i \omega}\right)\right|=0$ is a sufficient condition to indicate that " $y$ " does not cause " $x$ " at frequency " $\omega$ " (Tarı et al., 2012). The model proposed by Breitung and Candelon (2006) is based on the following linear limitations:

$$
\begin{aligned}
& \sum_{k=1}^{p} \Theta_{12, k} \cos (k \omega)=0 \\
& \sum_{k=1}^{p} \Theta_{12, k} \sin (\mathrm{k} \omega)=0
\end{aligned}
$$

Upon simplifying the above notations $\alpha_{j}=\Theta_{11, j}$ and $\beta_{j}=\Theta_{12, j}$ under linear restrictions, then the VAR equation for $x_{t}$ can be written as follows:

$$
\begin{aligned}
& x_{t}=\alpha_{1} x_{t-1}+\cdots+\alpha_{p} x_{t-p}+ \\
& +\beta_{1} y_{t-1}+\cdots+\beta_{p} y_{t-p}+\varepsilon_{1 t}
\end{aligned}
$$

Thus, the hypothesis $M_{y \rightarrow x}(\omega)=0$ is equivalent to the linear limitations, so the hypothesis $\mathrm{H}_{0}$ can be established as follows:

$\mathrm{H}_{0}: R(\omega) \beta=0\left(\beta=\left[\beta_{1, \ldots,} \beta_{p}\right]^{\prime}\right) R(\omega) \quad$ can be calculated by the following equation:
$R(\omega)=\left[\begin{array}{llll}\cos (\omega) & \cos (2 \omega) & \cdots & \cos (p \omega) \\ \sin (\omega) & \sin (2 \omega) & \cdots & \sin (p \omega)\end{array}\right]$

Since the test method has F-distribution of $(2, T-2 p)$ for $\omega \in(0, \pi)$, the standard $F$ test can be employed as causality measurement for $\mathrm{H}_{0}: R(\omega) \beta=0$.

\section{ESTIMATION RESULTS}

The Granger (1969) and Breitung and Candelon (2006) frequency domain causality analyses are performed in order to determine whether or not there is a causality relationship between the VIX, which is regarded as a fear index, and the daily percentage returns of the stock indexes of the countries included in the analysis.

G20 countries constitute the sample of the study in order to provide a wide dataset and restrict the sample to a perspective. The $\mathrm{G} 20$ countries consist of 19 countries including the EU commission, which can be classified as nine developed and ten developing countries. This situation not only yields a distinct perspective to the study, but also enables the results of developed and developing countries to be presented separately and provides an opportunity for comparison. In this context, the descriptive statistics of VIX index, stock index returns of developed and developing countries are presented in Table 2 and Table 3:

Upon examining Table 2, it is seen that NIKKEI225, NASDAQ100, and DAX are the top three indexes of developed countries with the highest average daily stock index returns, respectively. The top three index-

\begin{tabular}{|c|c|c|c|c|}
\hline Variables & Mean & Maximum & Minimum & Standard Deviation \\
\hline VIX Index & 16.1351 & 48.0000 & 9.2500 & 5.4660 \\
\hline CAC40 Index Returns & 0.00023 & 0.0574 & -0.0804 & 0.0137 \\
\hline DAX Index Returns & 0.00054 & 0.0643 & -0.0874 & 0.0136 \\
\hline FTSE100 Index Returns & 0.00017 & 0.0517 & -0.0600 & 0.0103 \\
\hline FTSEMIB Index Returns & 0.00008 & 0.0662 & -0.1248 & 0.0173 \\
\hline KOSPI Index Returns & 0.00041 & 0.0502 & -0.0622 & 0.0095 \\
\hline NASDAQ100 Index Returns & 0.00055 & 0.0884 & -0.1081 & 0.0117 \\
\hline NIKKEI225 Index Returns & 0.00075 & 0.0650 & -0.1004 & 0.0141 \\
\hline S\&P ASX200 Index Returns & 0.00026 & 0.0568 & -0.0396 & 0.0095 \\
\hline S\&P TSX Index Returns & 0.00012 & 0.0505 & -0.0404 & 0.0085 \\
\hline
\end{tabular}
es with the highest standard deviation are FTSEMIB, NIKKEI225, and CAC40 respectively. The descriptive statistics of stock index returns of developing countries are presented in Table 3.

Table 2. Descriptive statistics of developed countries 
Table 3. Descriptive statistics of developing countries

\begin{tabular}{lcccc}
\hline Variables & Mean & Maximum & Minimum & Standard Deviation \\
\hline BIST100 Index Returns & 0.00065 & 0.0693 & -0.1047 & 0.0151 \\
BOVESPA Index Returns & -0.00009 & 0.1084 & -0.0809 & 0.0161 \\
BSE 30 Index Returns & 0.00036 & 0.0516 & -0.0467 & 0.0104 \\
IDX Index Returns & 0.00052 & 0.0726 & -0.0888 & 0.0106 \\
JTOPI Index Returns & 0.00038 & 0.0479 & -0.0397 & 0.0104 \\
MERVAL Index Returns & 0.00168 & 0.1491 & -0.1073 & 0.0216 \\
MOEX Index Returns & 0.00034 & 0.0538 & -0.0782 & 0.0128 \\
SHANGHAI Index Returns & 0.00014 & 0.0692 & -0.1095 & 0.0164 \\
S\&P BMV IPC Index Returns & -0.00001 & 0.0425 & -0.0588 & 0.0092 \\
TADAWUL Index Returns & 0.00003 & 0.0892 & -0.0727 & 0.0104 \\
\hline
\end{tabular}

Upon examining Table 3, it is seen that MERVAL, BIST100, and IDX are the top three indexes of developing countries with the highest daily average stock index returns, respectively. The top three indexes with the highest standard deviation are MERVAL, SHANGHAI, and BOVESPA, respectively.

Before the causality analysis, the stability of the relevant time-series for all variables is tested with the conventional ADF and PP unit root tests. The VIX and the unit root test results of stock index returns of developed countries are presented in Table 4.
Upon examining the results presented in Table 4, it is seen that the VIX and stock index returns of developed countries do not contain unit root at a $1 \%$ significance level, meaning, the relevant time-series are stationary. The unit root test results of stock index returns of developing countries are presented in Table 5 .

Upon examining the results presented in Table 5, it is seen that developing countries do not contain a unit root at a $1 \%$ significance level, meaning, the related time-series are stationary. The stationarity of the series indicates that the relevant time-series tend

Table 4. Unit root test results for the indexes of developed countries

\begin{tabular}{|c|c|c|c|}
\hline \multirow{2}{*}{ Variable } & \multirow{2}{*}{ Constant-Trend } & ADF & PP \\
\hline & & t-stat. & t-stat. \\
\hline \multirow{2}{*}{ VIX Index } & Constant & $-4.6661 *$ & $-4.6227^{*}$ \\
\hline & Constant and Trend & $-5.5025^{*}$ & $-5.6250^{*}$ \\
\hline \multirow{2}{*}{ CAC40 Index Returns } & Constant & $-34.4027^{*}$ & $-34.8388^{*}$ \\
\hline & Constant and Trend & $-34.4294^{*}$ & $-34.9852^{*}$ \\
\hline \multirow[t]{2}{*}{ DAX Index Returns } & Constant & $-34.7495^{*}$ & $-34.8145^{*}$ \\
\hline & Constant and Trend & $-34.7522^{*}$ & $-34.8201^{*}$ \\
\hline \multirow{2}{*}{ FTSE100 Index Returns } & Constant & $-26.5604^{*}$ & $-36.6530^{*}$ \\
\hline & Constant and Trend & $-26.5829^{*}$ & $-36.8993^{*}$ \\
\hline \multirow{2}{*}{ FTSEMIB Index Returns } & Constant & $-35.6659 *$ & $-35.6664^{*}$ \\
\hline & Constant and Trend & $-35.7077^{*}$ & $-35.7778^{*}$ \\
\hline \multirow{2}{*}{ KOSPI Index Returns } & Constant & $-34.8166^{*}$ & $-34.9715^{*}$ \\
\hline & Constant and Trend & $-34.8041^{*}$ & $-34.9600^{*}$ \\
\hline \multirow{2}{*}{ NASDAQ100 Index Returns } & Constant & $-37.5281^{*}$ & $-37.9944^{*}$ \\
\hline & Constant and Trend & $-37.6309 *$ & $-38.3041^{*}$ \\
\hline \multirow{2}{*}{ NIKKEI225 Index Returns } & Constant & $-34.9839 *$ & $-35.2255^{*}$ \\
\hline & Constant and Trend & $-34.9703^{*}$ & $-35.2106^{*}$ \\
\hline \multirow{2}{*}{ S\&P ASX200 Index Returns } & Constant & $-35.4383^{*}$ & $-35.7044^{*}$ \\
\hline & Constant and Trend & $-35.4305^{*}$ & $-35.7002^{*}$ \\
\hline \multirow{2}{*}{ S\&P TSX Index Returns } & Constant & $-32.5777^{*}$ & $-33.0359^{*}$ \\
\hline & Constant and Trend & $-32.6212^{*}$ & $-33.2383^{*}$ \\
\hline
\end{tabular}

${ }^{*}$ significant at $1 \%$ level of significance. 
Table 5. Unit Root test results for the indexes of developing countries

\begin{tabular}{|c|c|c|c|}
\hline \multirow{2}{*}{ Variable } & \multirow{2}{*}{ Constant - Trend } & ADF & PP \\
\hline & & t-stat. & t-stat. \\
\hline \multirow{2}{*}{ BIST100 Index Returns } & Constant & $-35.2326^{*}$ & $-35.2791^{*}$ \\
\hline & Constant and Trend & $-35.2279 *$ & $-35.2777^{*}$ \\
\hline \multirow{2}{*}{ BOVESPA Index Returns } & Constant & $-33.1543^{*}$ & $-33.1757^{*}$ \\
\hline & Constant and Trend & $-33.2856^{*}$ & $-33.3420^{*}$ \\
\hline \multirow{2}{*}{ BSE 30 Index Returns } & Constant & $-33.7642^{*}$ & $-33.7656^{*}$ \\
\hline & Constant and Trend & $-33.7809^{*}$ & $-33.7810^{*}$ \\
\hline \multirow{2}{*}{ IDX Index Returns } & Constant & $-22.7918^{*}$ & $-33.8650^{*}$ \\
\hline & Constant and Trend & $-22.7832^{*}$ & $-33.8482^{*}$ \\
\hline \multirow{2}{*}{ JTOPI Index Returns } & Constant & $-35.3371^{*}$ & $-35.6609^{*}$ \\
\hline & Constant and Trend & $-35.3237^{*}$ & $-35.6466^{*}$ \\
\hline \multirow{2}{*}{ MERVAL Index Returns } & Constant & $-31.4113^{*}$ & $-31.3879 *$ \\
\hline & Constant and Trend & $-31.4718^{*}$ & $-31.4148^{*}$ \\
\hline \multirow{2}{*}{ MOEX Index Returns } & Constant & $-36.0318^{*}$ & $-36.0175^{*}$ \\
\hline & Constant and Trend & $-36.0648^{*}$ & $-36.0635^{*}$ \\
\hline \multirow{2}{*}{ SHANGHAI Index Returns } & Constant & $-35.5848^{*}$ & $-35.5523^{*}$ \\
\hline & Constant and Trend & $-35.5819^{*}$ & $-35.5497^{*}$ \\
\hline \multirow{2}{*}{ S\&P BMV IPC Index Returns } & Constant & $-25.4387^{*}$ & $-33.0365^{*}$ \\
\hline & Constant and Trend & $-25.4561^{*}$ & $-33.1375^{*}$ \\
\hline \multirow{2}{*}{ TADAWUL Index Returns } & Constant & $-33.9097^{*}$ & $-33.9049^{*}$ \\
\hline & Constant and Trend & $-33.8953^{*}$ & $-33.8902^{*}$ \\
\hline
\end{tabular}

* significant at $1 \%$ level of significance.

Table 6. Granger causality analysis results for developed countries

\begin{tabular}{|l|l|c|l|l|}
\hline Direction of Causality & $\begin{array}{l}\text { F-statistics } \\
\text { (Prob.) }\end{array}$ & Lags & Causality & Correlation \\
\hline VIX $\rightarrow$ CAC40 Index Returns & $8.4755^{*}$ & 8 & The VIX Granger-causes the change in the CAC40. & -0.16 \\
\hline VIX $\rightarrow$ DAX Index Returns & $2.2007^{* *}$ & 8 & The VIX Granger-cause the change in the DAX. & -0.17 \\
\hline VIX $\rightarrow$ FTSE100 Index Returns & $18.3608^{*}$ & 5 & The VIX Granger-causes the change in the FTSE100. & -0.13 \\
\hline VIX $\rightarrow$ FTSEMIB Index Returns & $8.2098^{*}$ & 8 & The VIX Granger-causes the change in the FTSEMIB. & -0.16 \\
\hline VIX $\rightarrow$ KOSPI Index Returns & $22.2726^{*}$ & 8 & The VIX Granger-causes the change in the KOSPI. & -0.11 \\
\hline VIX $\rightarrow$ NASDAQ100 Index Returns & 1.0402 & 4 & $\begin{array}{l}\text { The VIX does not Granger-cause the change in the } \\
\text { NASDAQ100. }\end{array}$ & -0.22 \\
\hline VIX $\rightarrow$ NIKKEI225 Index Returns & $19.7902^{*}$ & 4 & The VIX Granger-causes the change in the NIKKEI225. & -0.13 \\
\hline VIX $\rightarrow$ S\&P ASX200 Index Returns & $34.8102^{*}$ & 4 & $\begin{array}{l}\text { The VIX Granger-causes the change in the S\&P } \\
\text { ASX200. }\end{array}$ & -0.11 \\
\hline VIX $\rightarrow$ S\&P TSX Index Returns & $2.48537^{* *}$ & 4 & The VIX Granger-causes the change in the S\&P TSX. & -0.15 \\
\hline
\end{tabular}

* significant at $1 \%$ level of significance. ${ }^{* *}$ significant at $5 \%$ level of significance.

to imply mean-reverting behavior and the series can be predicted. Accordingly, the mean and variance of the relevant time-series are constant. Thus, causality analysis can be performed on the series. On the other hand, lag lengths influence the success of the analysis. In this study, lag lengths are determined according to the Akaike Information Criterion since it is more generous than the other information criteria. Table 6 presents the Granger causality analysis results running from the VIX towards the stock index returns of developed countries.
According to the Granger causality analysis results presented in Table 6, the VIX Granger causes CAC40, DAX, FTSEMIB, FTSE100, KOSPI, NIKKEI225, S\&P ASX200, and S\&P TSX indexes. In other words, the VIX influences these index returns. Nevertheless, there is no causality running from the VIX towards NASDAQ100 indexes. Upon considering the correlation coefficients, it can be seen that the increase in the VIX has a negative correlation with the related index returns. Table 7 presents the Granger causality analysis results obtained from the VIX towards the stock 
Table 7. Granger causality analysis results for developing countries

\begin{tabular}{|l|c|c|l|c|}
\hline Direction of Causality & $\begin{array}{c}\text { F-statistics } \\
\text { (Prob.) }\end{array}$ & Lags & \multicolumn{1}{|l|}{ Causality } & Correlation \\
\hline VIX $\rightarrow$ BIST100 Index Returns & 1.4068 & 3 & $\begin{array}{l}\text { The VIX does not Granger-cause the change in the } \\
\text { BIST100. }\end{array}$ & -0.08 \\
\hline VIX $\rightarrow$ BOVESPA Index Returns & 0.61211 & 3 & $\begin{array}{l}\text { The VIX does not Granger-cause the change in the } \\
\text { BOVESPA. }\end{array}$ & -0.11 \\
\hline VIX $\rightarrow$ BSE30 Index Returns & $10.4531^{*}$ & 4 & The VIX Granger-causes the change in the BSE30. & -0.14 \\
\hline VIX $\rightarrow$ IDX Index Returns & $10.8795^{*}$ & 7 & The VIX Granger-causes the change in the IDX. & -0.08 \\
\hline VIX $\rightarrow$ JTOPI Index Returns & $13.7315^{*}$ & 4 & The VIX Granger-causes the change in the JTOPI & -0.11 \\
\hline VIX $\rightarrow$ MERVAL Index Returns & 0.69698 & 4 & $\begin{array}{l}\text { The VIX does not Granger-cause the change in the } \\
\text { MERVAL. }\end{array}$ & -0.13 \\
\hline VIX $\rightarrow$ MOEX Index Returns & $3.9156^{*}$ & 4 & The VIX Granger-causes the change in the MOEX. & -0.11 \\
\hline VIX $\rightarrow$ SHANGAI Index Returns & $4.9357^{*}$ & 5 & The VIX Granger-causes the change in the SHANGAI. & -0.09 \\
\hline $\begin{array}{l}\text { VIX } \rightarrow \text { S\&P BMV IPC Index } \\
\text { Returns }\end{array}$ & 1.6697 & 6 & $\begin{array}{l}\text { The VIX does not Granger-cause the change in the } \\
\text { S\&P/BMV IPC. }\end{array}$ & -0.12 \\
\hline $\begin{array}{l}\text { VIX } \rightarrow \text { TADAWUL Index } \\
\text { Returns }\end{array}$ & 0.3625 & 5 & $\begin{array}{l}\text { The VIX does not Granger-cause the change in the } \\
\text { S\&P/BMV IPC. }\end{array}$ & -0.07 \\
\hline
\end{tabular}

${ }^{*}$ significant at $1 \%$ level of significance

index returns of developing countries.

According to the Granger causality analysis results presented in Table 7, the VIX Granger causes the stock index returns of BSE30, IDX, JTOPI, MOEX and SHANGAI, stock index returns. However, there is no causality running from the VIX to BIST100, BOVESPA, MERVAL, S\&P/BMV IPC, and TADAWUL stock market index returns.

Upon considering the correlation coefficients, it can be seen that the increases in the VIX are negatively correlated with the related index returns. The Granger (1969) causality test and the Breitung and Candelon (2006) frequency domain causality test use the same lag lengths regardless of having different assumptions. In this respect, while Granger (1969) finds a single causality result for the entire analysis period, Breitung and Candelon (2006) reveal different results in the short-, medium- and long-run through the unit circle. Accordingly, it would be suggested that the
Breitung and Candelon (2006) frequency domain causality test reveals more detailed results (İskenderoğlu and Akdağ, 2017: 631). In Table 8, the results of the Breitung and Candelon frequency domain causality analysis between the VIX and stock index returns of the selected countries are reported separately for the long- and short-run. In the causality analysis, the lag length determined by the Akaike Information Criterion is applied in coordination with the Granger causality analysis. In the Breitung and Candelon (2006) frequency domain causality test, the period lengths are calculated based on the $2 \pi / f_{X}(\omega)$ the formula, which represents the perimeter of the unit circle. In this context, term lengths correspond to 13-63-day intervals in the long-run, 4 - 7-day intervals in the medium-run and 2 - 3-day intervals in the short-run. Table 8 presents the results of the Breitung and Candelon (2006) frequency domain causality analysis between the VIX and stock index returns of developed countries.

Table 8. The Breitung and Candelon frequency domain causality analysis results for developed countries

\begin{tabular}{|l|l|l|l|l|l|l|}
\hline \multirow{2}{*}{ Direction of Causality } & \multicolumn{2}{|c|}{ Long-term } & \multicolumn{2}{c|}{ Medium-term } & \multicolumn{2}{c|}{ Short-term } \\
\cline { 2 - 7 } & \multicolumn{1}{|c|}{$\mathrm{W}=0.1$} & $\mathrm{~W}=0.5$ & $\mathrm{~W}=1$ & $\mathrm{~W}=1.5$ & $\mathrm{~W}=2$ & $\mathrm{~W}=2.5$ \\
\hline $\mathrm{VIX} \rightarrow$ CAC40 & $26.5592^{*}$ & $38.6658^{*}$ & $45.9459^{*}$ & $34.7809^{*}$ & $24.2102^{*}$ & $30.9439^{*}$ \\
\hline $\mathrm{VIX} \rightarrow \mathrm{DAX}$ & 3.7935 & 0.4518 & $12.5205^{*}$ & $6.9877^{* *}$ & 3.5435 & 4.0792 \\
\hline VIX $\rightarrow$ FTSE100 & $19.1327^{*}$ & $40.6248^{*}$ & $34.2792^{*}$ & $27.7060^{*}$ & $25.8081^{*}$ & $17.3528^{*}$ \\
\hline VIX $\rightarrow$ FTSEMIB & $12.3807^{*}$ & 3.1733 & $49.5211^{*}$ & $25.3957^{*}$ & $9.5378^{*}$ & $14.4033^{*}$ \\
\hline VIX $\rightarrow$ KOSPI & $27.2659^{*}$ & $42.3386^{*}$ & $67.5279^{*}$ & $17.0068^{*}$ & $92.4582^{*}$ & $30.5930^{*}$ \\
\hline VIX $\rightarrow$ NASDAQ100 & 4.1447 & 1.5367 & 0.4545 & 0.2214 & 0.0106 & 0.0803 \\
\hline VIX $\rightarrow$ NIKKEI225 & $37.8764^{*}$ & $44.7072^{*}$ & $51.0291^{*}$ & $32.7997^{*}$ & $31.8189^{*}$ & $51.2505^{*}$ \\
\hline VIX $\rightarrow$ S\&P ASX200 & $37.1116^{*}$ & $76.4640^{*}$ & $95.0779^{*}$ & $73.8249^{*}$ & $82.8067^{*}$ & $43.9802^{*}$ \\
\hline VIX $\rightarrow$ S\&P TSX & 0.4821 & $7.1607^{* *}$ & $9.9088^{*}$ & $9.7513^{*}$ & $9.4382^{*}$ & $9.4011^{*}$ \\
\hline
\end{tabular}

${ }^{*}$ significant at $5 \%$ level of significance. ${ }^{* *}$ significant at $1 \%$ level of significance. 
Table 9. The Breitung and Candelon frequency domain causality analysis results for developing countries

\begin{tabular}{|l|l|l|l|l|l|l|}
\hline \multirow{2}{*}{ Direction of Causality } & \multicolumn{2}{|c|}{ Long-term } & \multicolumn{2}{c|}{ Medium-term } & \multicolumn{2}{c|}{ Short-term } \\
\cline { 2 - 7 } & \multicolumn{1}{|c|}{$\mathrm{W}=0.1$} & $\mathrm{~W}=0.5$ & $\mathrm{~W}=1$ & $\mathrm{~W}=1.5$ & $\mathrm{~W}=2$ & $\mathrm{~W}=2.5$ \\
\hline $\mathrm{VIX} \rightarrow$ BIST100 & 3.6611 & 4.1393 & 3.9755 & 3.7042 & 3.6017 & 3.5601 \\
\hline $\mathrm{VIX} \rightarrow$ BOVESPA & 0.5242 & 0.5507 & 0.9751 & 1.0917 & 1.1178 & 1.1259 \\
\hline $\mathrm{VIX} \rightarrow$ BSE30 & $22.2677^{*}$ & $27.2242^{*}$ & $36.7668^{*}$ & $30.2325^{*}$ & $19.5817^{*}$ & $21.4649^{*}$ \\
\hline VIX $\rightarrow$ IDX & 0.7148 & $13.7302^{*}$ & $7.0171^{* *}$ & $38.3462^{*}$ & $42.7631^{*}$ & 3.5011 \\
\hline VIX $\rightarrow$ JTOPI & $13.3089^{*}$ & $36.9554^{*}$ & $51.8090^{*}$ & $46.5070^{*}$ & $40.1801^{*}$ & $42.6004^{*}$ \\
\hline VIX $\rightarrow$ MERVAL & 0.0739 & 1.1161 & 2.3101 & 2.5916 & 2.7603 & 2.7040 \\
\hline VIX $\rightarrow$ MOEX & $9.5561^{*}$ & $11.1329^{*}$ & $10.5086^{*}$ & 5.4403 & 4.5438 & $8.6569^{* *}$ \\
\hline VIX $\rightarrow$ SHANGAI & $6.1706^{* *}$ & $16.1288^{*}$ & $16.7150^{*}$ & $13.2019^{*}$ & $6.5557^{* *}$ & $7.2248^{* *}$ \\
\hline VIX $\rightarrow$ S\&P BMV IPC & 1.4054 & 5.2811 & 3.8196 & 0.6641 & 1.4924 & $6.3605^{* *}$ \\
\hline VIX $\rightarrow$ TADAWUL & 0.1398 & 1.2230 & 1.6284 & 1.6775 & 0.9526 & 0.2366 \\
\hline
\end{tabular}

${ }^{*}$ significant at $1 \%$ level of significance. ${ }^{* *}$ significant at $5 \%$ level of significance.

According to the results of the frequency domain causality analysis in Table 8 , the causality relationships are detected running from the VIX toward CAC40, FTSEMIB, FTSE100, KOSPI, NIKKEI225, S\&P ASX200, and S\&P TSX indexes in the short-, medium- and long-run. Accordingly, the existence of a permanent causal relationship between the VIX and the stock exchange index returns of countries can be mentioned. Besides only a medium-term causal relationship is found on VIX towards DAX. However, similar to the analysis of Granger causality, a causal relationship between the VIX and NASDAQ100 index returns cannot be detected in Breitung and Candelon frequency domain causality analysis. Graphical illustrations of the frequency domain causality analysis results for developed countries are presented in Annex 1. Table 9 presents the results of the Breitung and Candelon (2006) frequency domain causality analysis between the VIX and stock index returns of developing countries.

According to the results of the frequency domain causality analysis in Table 9, the causal relationships are detected running from the VIX to BSE30, IDX, JTOPI, MOEX, and SHANGAI indexes in the short-, medium- and long-run. Accordingly, the existence of a permanent causal relationship between the VIX and the stock exchange index returns of these countries can be mentioned. Besides, a causal relationship from the VIX to S\&P BMV IPC index is found in the shortrun. Nevertheless, no causal relationship is detected from the VIX to the BIST100, BOVESPA and MERVAL index returns. It can be said that the BIST100, BOVESPA, MERVAL and TADAWUL index returns are not causally affected by the VIX. Graphical illustrations of the frequency domain causality analysis results for developing countries are presented in Annex 2.

\section{CONCLUSIONS AND SUGGESTIONS}

Investors manage investment decisions in accordance with risks and returns. As the market risk increases, it is expected that investors would exhibit a risk-averse attitude due to the increasing information asymmetry. As a consequence, such investors may be expected to reduce the purchase price of stocks or to sell their existing stocks. In this case, bond prices are expected to decrease and decrease in the indicator indexes are expected to decline as well as the index returns. In this study, the presence of a causal relationship between the VIX, also known as the fear index, and stock exchange index returns of G20 countries is investigated. The G20 countries are selected to conduct the study in a very broad perspective. G20 countries consist of nine developed countries (Australia, France, Canada, Germany, Italy, Japan, South Korea, UK and USA) and ten developing countries (Argentina, Brazil, China, India, Indonesia, Mexico, Russia, South Africa, Saudi Arabia and Turkey) whereas one of the 20 countries is known as the European Union Commission. In this regard, there could have been only 19 countries in the G20 sample. The casuality between VIX and index returns is examined by the Granger (1969) and the Breitung and Candelon (2006) frequency domain causality analyses.

The results obtained from the study assert that the short-, medium- and long-term causal relationships are detected running from the VIX to 7 of 9 index returns of developed countries, namely; CAC40, FTSEMIB, FTSE100, KOSPI, NIKKEI225, S\&P ASX200, and S\&P TSX. While the causal relationship from the VIX to DAX index return is found only in the medium-run, however, the only exception of this causal relationship results in developed countries is NASDAQ100. 
There is no causal relationship running from the VIX to NASDAQ100 index return. Upon evaluating the issue in terms of developing countries, the short-, medium- and long-term causal relationships are determined between the VIX and 5 of 10 index returns of developing countries, namely; BSE30, IDX, JTOPI, MOEX and SHANGAI. The causal relationship from the VIX to S\&P BMV IPC index is found only in the shortrun, whereas no causal relationship is detected which runs from the VIX to the BIST100, BOVESPA, MERVAL and TADAWUL index returns.

While the aim of the study concentrates to reveal the potential causal effect of VIX on developed and developing stock markets, it can be said that the effect is more common on developed countries. The reason behind this result can be explained by the strong form efficiency of capital markets of developed countries.

Upon evaluating the analysis results collectively, it can be said that there is a causal relationship between the VIX and the stock exchange index returns of developed and developing countries with the exceptions mentioned above. However, the causal relationship is more likely to be found in developed countries in comparison to developing countries. The slight difference should be explicated with further analysis for country-specific effects.

The results of this study are partially supported by the findings of Korkmaz and Çevik (2009) who found that the VIX affects the stock exchange indexes of various countries such as Argentina, Brazil, Russia, Indonesia, South Korea, and Turkey, and Sarwar and Khan (2017) who detected a negative and significant causal relationship between the VIX and the stock exchange indexes of the Latin American countries. Besides, Öner et. al. (2008) found similar results of no causal relationship between the VIX and MERVAL indexes. However, Sarwar (2012) found a significant correlation between the VIX and the US stock exchange indexes and no such relation with Russia's stock exchange index. A contradiction between the results and examined periods of the studies can be attributed to the main reason for this situation.

Upon evaluating the obtained results from the study regarding investors, it is suggested that the VIX for investors trading in the NASDAQ, BIST100, BOVESPA, MERVAL, S\&P BMV IPC and TADAWUL stock markets is not a determining factor in the investment process, unlike other determinants. However, it can be claimed that the VIX would affect stock returns in other sample countries. In terms of capital market institutions, the results are suggestive for monitoring the VIX which may be useful to understand capital market movements.

When the results are evaluated from the point of view of investors, it can be suggested that they include the stocks included in the NASDAQ100, BIST100, BOVESPA, MERVAL, S\&P BMV IPC and TADAWUL indexes in the portfolio diversification during the period of VIX. In the declining period of VIX, it may be recommended to invest in stocks in developed countries' indices, except for the NASDAQ100 index.

The results of this study, which examines the causality relationship between the VIX the indicator indexes of the selected countries, can only be applied to those countries. In other words, the results of the study should not be considered beyond the scope of examined countries. In future studies to be conducted, the analysis may contribute to the literature in the sense that the inclusion of the data from more countries and longer periods for the analysis would generalize the obtained results.

\section{REFERENCES}

Aggarwal, R., Inclan, C. \& Leal, R. 1999. Volatility in emerging stock markets. Journal of Financial and Quantitative Analysis, 34(1): 33-55.

Akdağ, S., Kiliç, İ., \& Yildirim, H. 2019. Does VIX scare stocks of tourism companies?. Letters in Spatial and Resource Sciences, 12(3): 215-232.

Balke, N.S. \& Fomby, T.B. 1997. Threshold cointegration. International Economic Review, 38(3): 627-645.

Başoğlu, U., Ceylan, A. \& Parasız, İ. 2001. Finance: Theory, institutions and tools (1. Ed). Bursa:Ekin Publishing House

Bildik, R. \& Elekdag, S. 2004. Effects of price limits on volatility: Evidence from the Istanbul stock exchange. Emerging Markets Finance and Trade, 40(1): 5-34.

Black, F. \& Scholes, M. 1973. The pricing of options and corporate liabilities. Journal of Political Economy, 81(3): 637-654.

Bloomberg. World Stock Exchanges. 2018. https://www. bloomberght.com/borsa/dunya-borsalari, Accessed 2 February 2018.

Bodart, V. \& Candelon, B. 2009. Evidence of interdependence and contagion using a frequency domain framework. Emerging Markets Review, 10(2): 140-150.

Breitung, J. \& Candelon, B. 2006. Testing for short and longrun causality: a frequency domain approach. Journal of Econometrics, 132(2): 363-378.

Campbell, J. C. \& Perron, P. 1991. Pitfall and opportunities: what macroeconomists should know about unit roots. NBER Technical Working Paper. http://www.journals. uchicago.edu/doi/pdfplus/10.1086/654163, (accessed February 7, 2017).

Chen, J., Jiang, F., Liu, Y., \& Tu, J. 2017. International volatility risk and Chinese stock return predictability. Journal of International Money and Finance, 70: 183-203. 
Cheuathonghua, M., Padungsaksawasdi, C., Boonchoo, P., \& Tongurai, J. 2019. Extreme spillovers of VIX fear index to international equity markets. Financial Markets and Portfolio Management, 33(1): 1-38.

Chicago Board Options Exchange. VIX (2018). http://www. cboe.com/delayedquote/detailed-quotes?ticker=VIX, (accessed February 2, 2018.

Ciner, Ç. 2011. Eurocurrency interest rate linkages: a frequency domain analysis. International Review of Economics and Finance, 20(4): 498-505.

CNBC. Stock Markets 2018. https://www.cnbc.com/markets/ , (accessed February 8, 2018).

Drake, P.P. \& Fabozzi, F.J. 2010. The Basics of finance (1.Ed). Canada: John Wiley \& Sons.

Erdoğdu, H. \& Baykut, E. 2016. The analysis of the relationship between the BIST banking index (XBANK) and the indices of VIX and MOVE. Journal of Banker, 98: 57-72.

Granger, C.W.J. 1969. Investigating causal relations by econometric models and cross-spectral methods. Econometrica, 37(3): 424-438.

Granger, C.W.J. 1988. Some recent development in a concept of causality. Journal of Econometrics, 39(1-2): 199-211.

Geweke, J. 1982. Measurement of linear dependence and feedback between multiple time series. Journal of the American Statistical Association, 77(378): 304-313.

Han, H., Kutan, A. M. \& Ryu, D. 2015. Effects of the US stock market return and volatility on the VKOSPI. Economics: The Open-Access, Open-Assessment E-Journal, 9(201535): 1-34

Heinonen, A. 2013. The fear gauge-VIX volatility index and the time-varying relationship between implied volatility and stock returns. Master's Thesis, Faculty of Social Sciences Economics, University of Helsinki

Hosoya Y. 1991. The decomposition and measurement of the interdependency between second-order stationary processes. Probability Theory Relat Fields, 88(4): 429-444.

Huang, T. C. \&Wang, K. Y. 2017. Investors'fear and herding behavior: evidence from the taiwan stock market. Emerging Markets Finance and Trade, 53(10): 2259-2278.

İskenderoğlu, Ö. \& Akdağ, S. 2017. Investigation of the validity of financial services confidence index: the case of Turkey. International Journal Of Economic Studies, 3(4): 625-633.

Kaya, A., Güngör, B. \& Özçomak, M.S. 2014. Is VIX index a fear index for investors? OECD countries stock exchange example with ARDL approach. Paper presented at the annual meeting of the First Middle East Conference on Global Business, Economics, Finance and Banking (ME14 DUBAI Conference) Dubai.

Kaya, A. \& Çoşkun, A. 2015. Is VIX index causality stock exchange? Istanbul stock exchange example. Cumhuriyet University, Journal of Economics and Administrative Sciences, 16(1): 175-186.
Korkmaz, T. \& Çevik, E. İ. 2009. Volatility Spillover Effect from Volatility Implied Index to Emerging Markets. Journal of BRSA Banking \& Financial Markets, 3(2): 87-105.

Kratschell, K. \& Schmidt, T. 2012. Long-run trends or shortrun fluctuations - What establishes the correlation between oil and food prices? Ruhr Economic Paper, 357: 3-19.

Kula, V \& Baykut, E. 2017. Analysis of the relationship between bist corporate governance index (XKURY) and the fear index (Chicago board options exchange volatility index-VIX). Afyon Kocatepe University Journal of Economics and Administrative Sciences, 19(2): 27-37.

Merton, R. C. 1973. Theory of rational option pricing. The Bell Journal of Economics and Management Science, 4(1): 141-183.

Nazlioglu, S., Hammoudeh, S., \& Gupta, R. 2015. Volatility transmission between Islamic and conventional equity markets: Evidence from causality-in-variance test. Applied Economics, 47(46): 4996-5011.

Nelson, C.R. \& Plosser, C.R. 1982. Trends and random walks in macroeconomic time series: Some evidence and implications. Journal of Monetary Economics, 10(2): 139-162.

Ozair, M. 2014. What does the VIX actually measure? An analysis of the causation of SPX and VIX. ACRN Journal of Finance and Risk Perspectives, 3(2): 83-132.

Öner, H., Içellioğlu, C. Ş., \& Öner, S. 2018. The engel-granger cointegration and granger causality analysis between volatility index (VIX) and developing country stock market indices. Journal of Financial Researches and Studies, 10(18):110-124.

Qadan, M., Kliger, D., \& Chen, N. 2019. Idiosyncratic volatility, the VIX and stock returns. The North American Journal of Economics and Finance, 47: 431-441.

Sarwar, G. 2012. Is VIX an investor fear gauge in BRIC equity markets?. Journal of Multinational Financial Management, 22(3): 55-65.

Sarwar, G. \& Khan, W. 2017. The effect of us stock market uncertainty on emerging market returns. Emerging Markets Finance and Trade, 53(8): 1796-1811.

Saraç, T. B., İskenderoğlu, Ö. \& Akdağ, S. 2016. Investigation of domestic and foreign investors' risk appetite: The Case of Turkey. Sosyoekonomi, 24(30): 29-44.

Schmukler, S. L., Zoido, P., \& Halac, M. 2003. Financial globalization, crises, and contagion. Globalization World Bank Policy Research Report, 1-30.

Schwert, G.W. 2002. Tests for unit roots: A monte carlo investigation. Journal of Business \& Economic Statistics, 20(1): 5-17.

Tarı,R., Abasız, T. \& Pehlivanoğlu, F. 2012. Causality relationship between the TEFE and TUFE: A frequency domain approach. Akdeniz University Faculty of Economics \& Administrative Sciences Faculty Journal, 24: 1-15. 
Yanfeng, W. 2013. The dynamic relationships between oil prices and the Japanese economy: A frequency domain analysis. Review of Economics \& Finance, 3: 57-67.

Yao, F. \& Hosoya, Y. 2000. Inference on one-way effect and evidence in Japanese macroeconomic data. Journal of Econometrics, 98(2): 225-255.

Yule, G.U. 1926. Why do we sometimes get nonsense-correlations between time-series?--A study in sampling and the nature of time-series. Journal of the Royal Statistical Society, 89(1): 1-63. 
Annex 1. Graphics for Breitung-Candelon frequency domain causality analysis results of developing countries

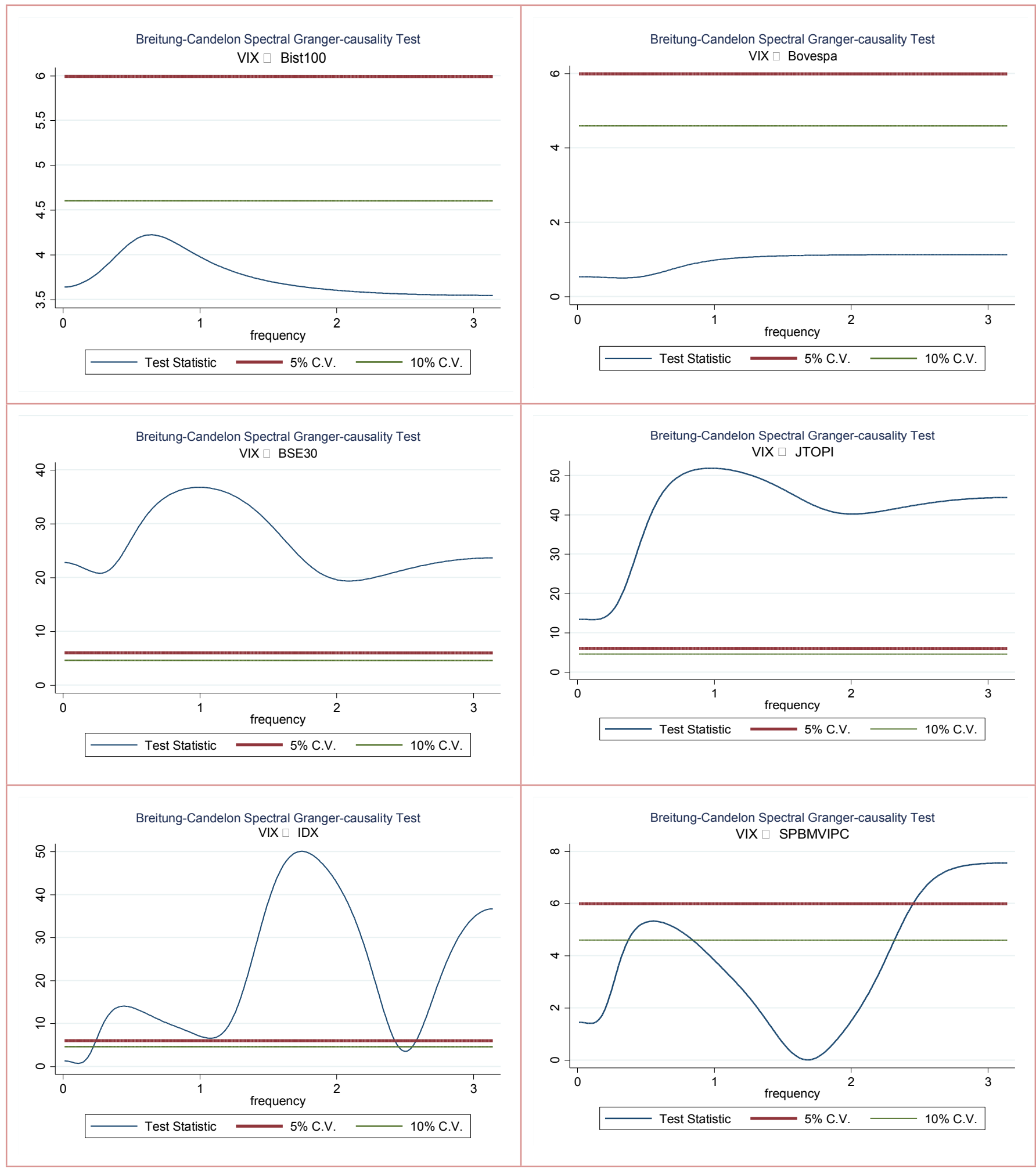




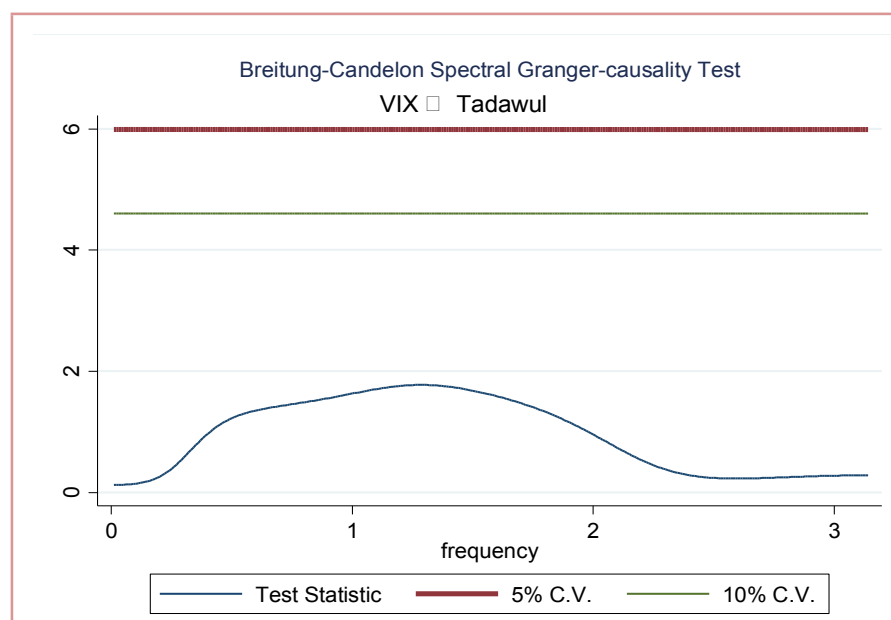

Breitung-Candelon Spectral Granger-causality Test
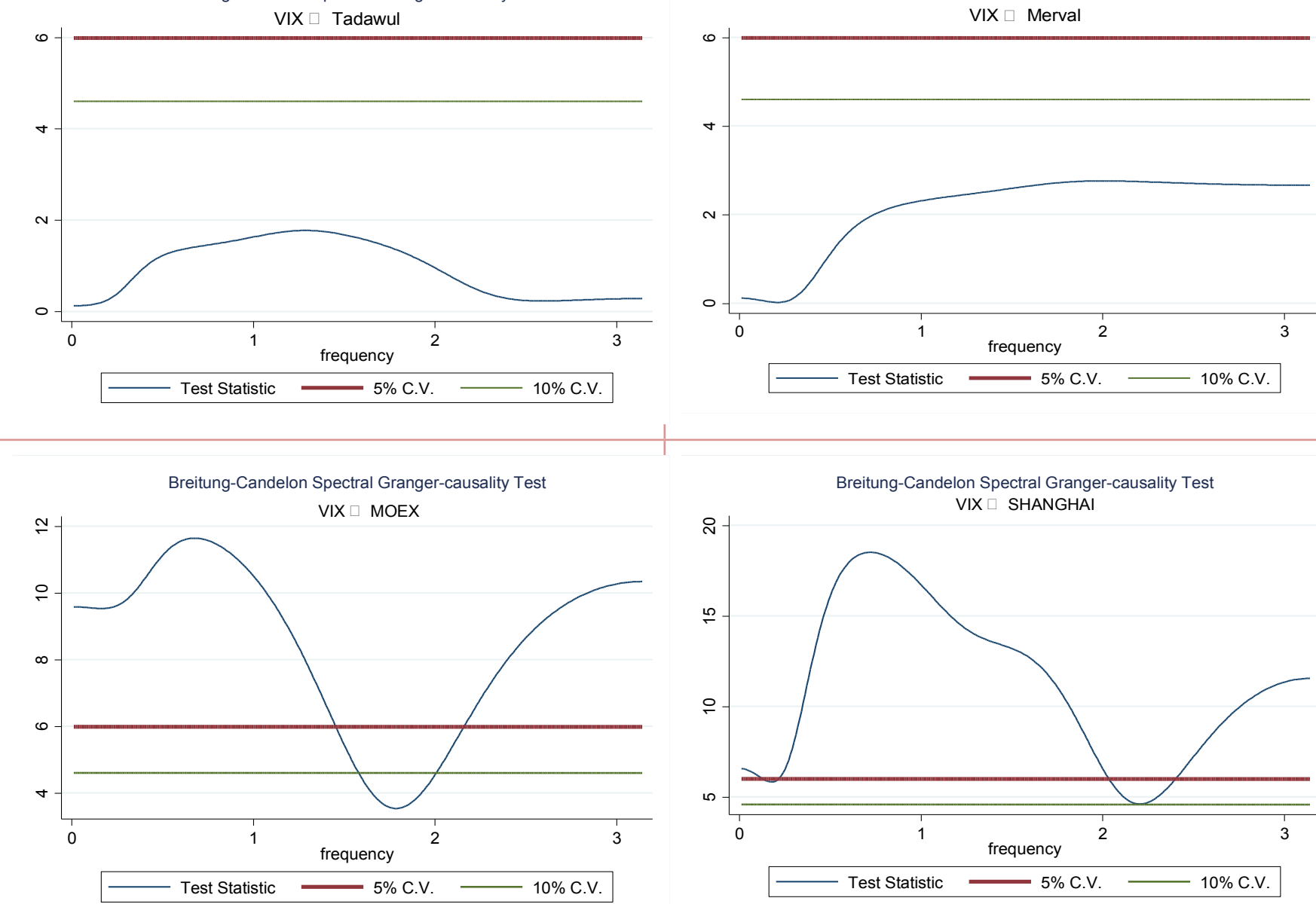

Breitung-Candelon Spectral Granger-causality Test

$$
\text { VIX } \square \text { SHANGHAI }
$$

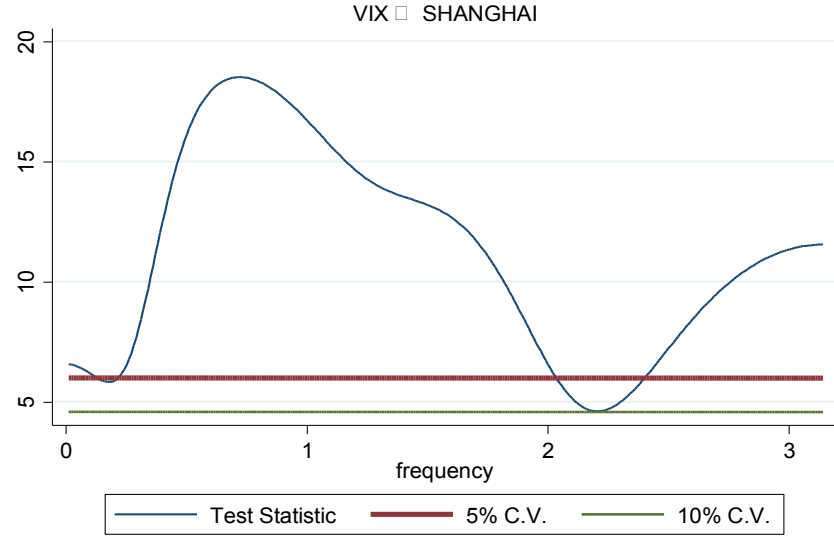


Annex 2. Graphics for Breitung-Candelon frequency domain causality analysis results of developed countries

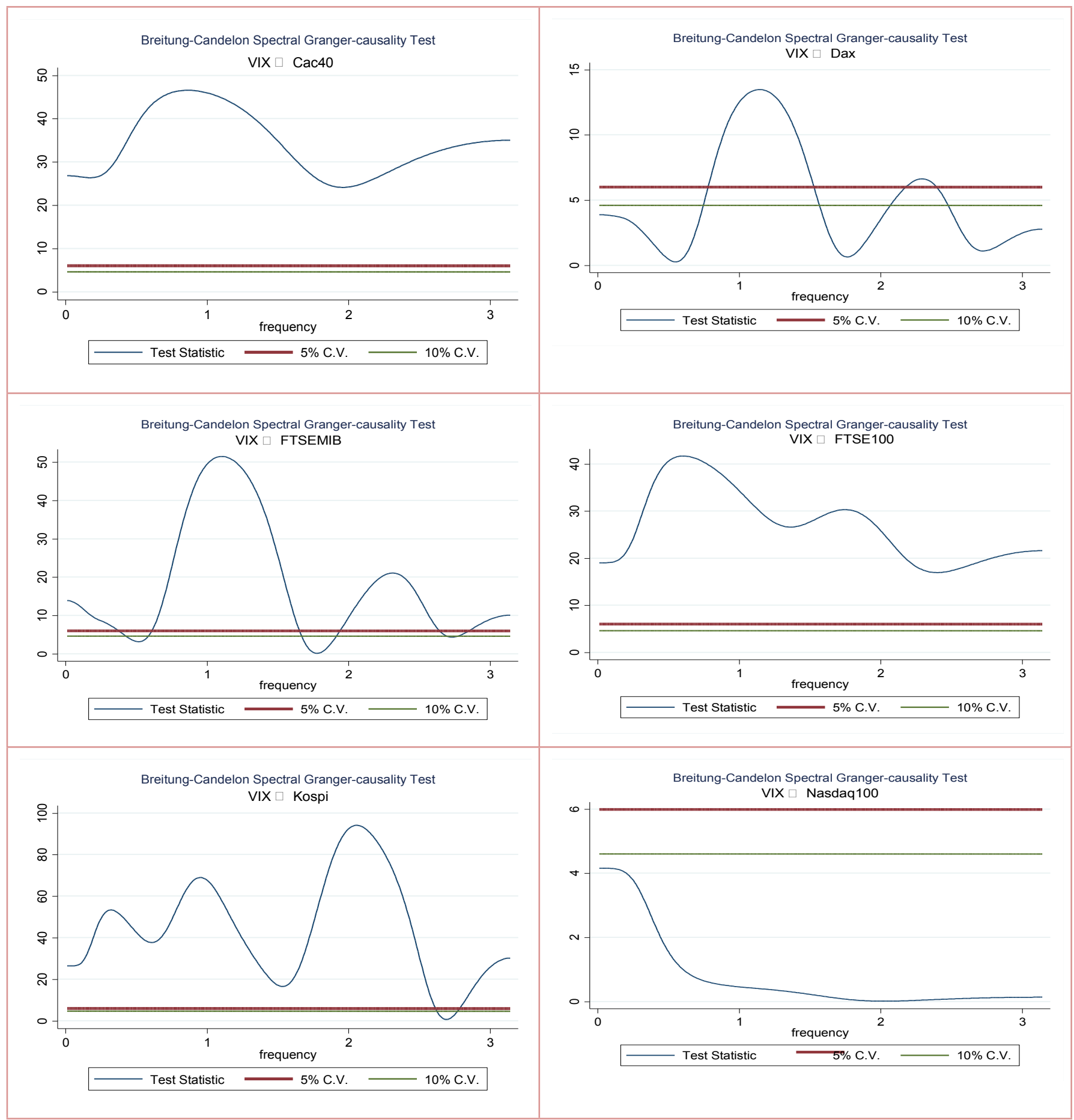




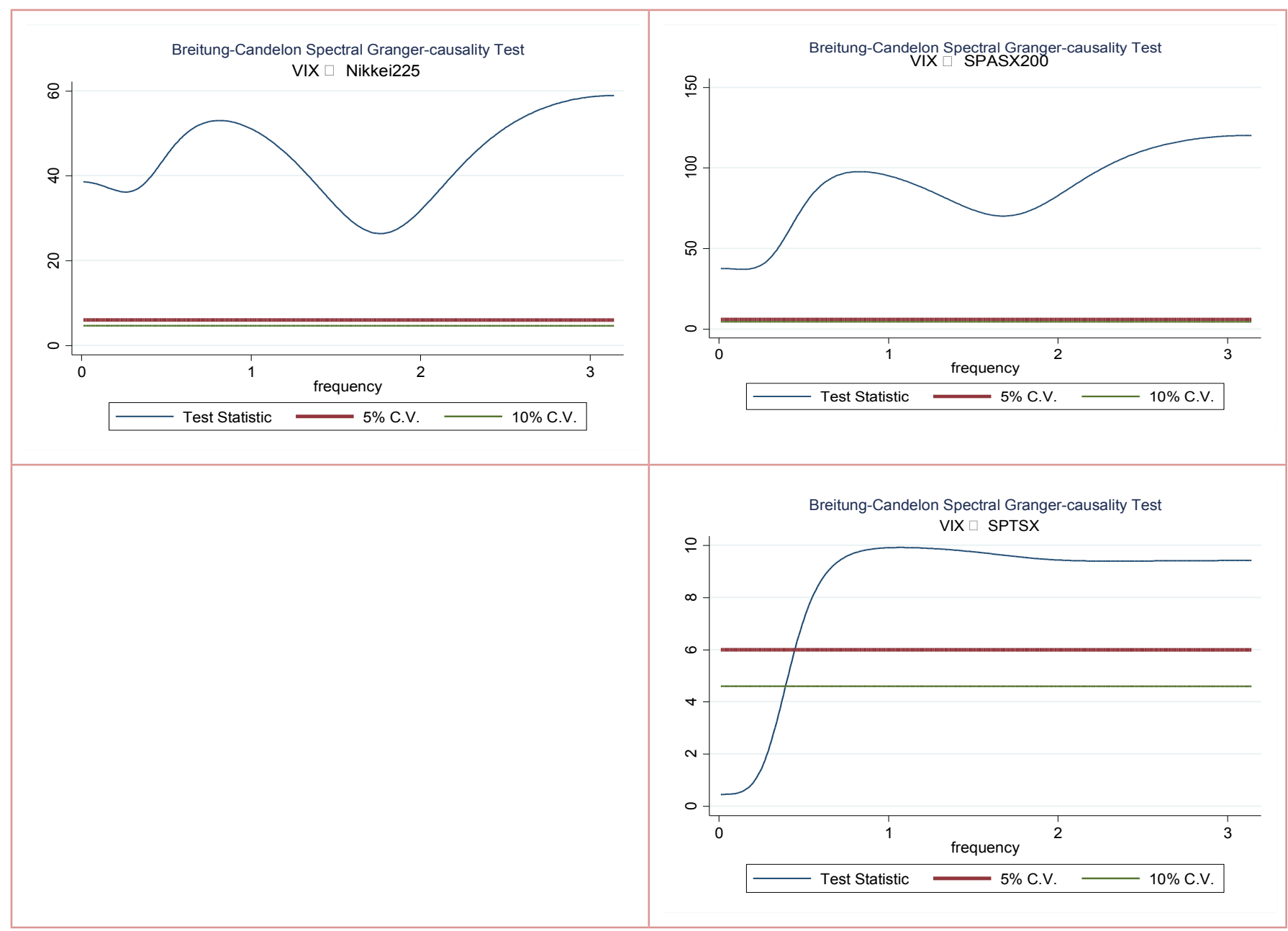

